$\mathrm{C}-\mathrm{A} / \mathrm{AP} / \# 224$

November 2005

\title{
Analysis and Design of Cold Helium Gas Warm Up for the $2 \mathrm{~K}$ Experiment
}

\author{
Olive Stohlman - Carnegie Melon University \\ John Krupczak, Jr. - Hope College \\ Ahmed Sidi-Yekhlef - Brookhaven National Laboratory
}

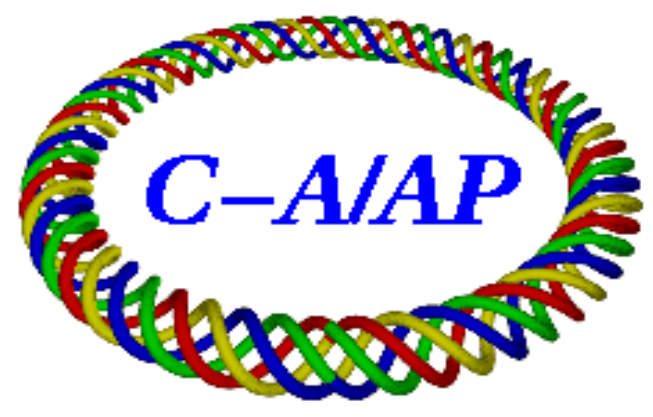

Collider-Accelerator Department

Brookhaven National Laboratory

Upton, NY 11973 
Analysis and Design of Cold Helium Gas Warm Up for the 2K Experiment

\author{
Olive Stohlman \\ Carnegie Melon University \\ John Krupczak, Jr. \\ Hope College \\ Ahmed Sidi-Yekhlef \\ Brookhaven National Laboratory
}

November 11, 2005 


\section{$\underline{\text { Overview }}$}

This file models the heating of helium gas from $11 \mathrm{~K}$ to a goal of at least $280 \mathrm{~K}$. The purpose is to demonstrate the feasibility of an ambient vaporizer for this application, given the low pressure drop available.

The setup is a 100-foot Schedule 2010 " steel pipe leading into a vaporizer with some number of parallel, finned 1" pipes.

Results suggest that the proposed setup with 18 parallel vaporizer tubes will suffice, under the condition that about half of the leading 10" pipe be ice-free and open to natural convection. This section is pipe is valuable for the larger part of the heating operation and requires little pressure drop to maintain an acceptable flow rate. It is still advantageous to have a significant portion of the warm-up occur in the ambient vaporizer bank, because the cold gas demands less pressure drop to move through the pipe- thus, the more heating done at the end of the gas's travel, the less pressure drop needed. 


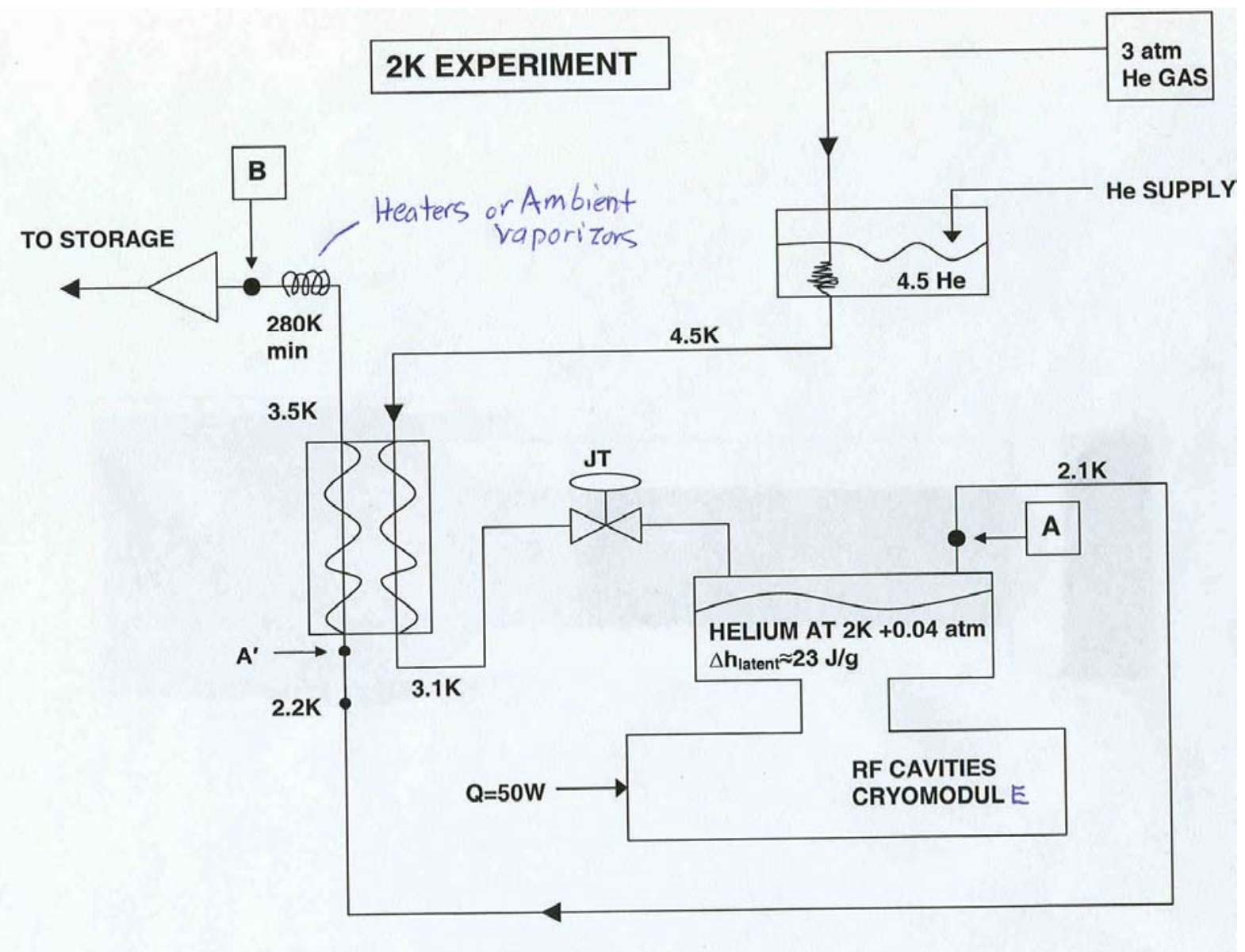

System Schematic 


\section{Model Structure}

There are currently four submodels to this simulation: one fluid submodel (containing two HX macros), and three thermal submodels- the 10" tube, an ambient vaporizer tube, and a fin.

\section{BigFlow}

The fluid submodel, "BigFlow," defines the starting conditions and pumping conditions of the helium. Currently, the pump is modeled as a defined mass flow rate, rather than any complex pumping relationship between pressure and volume flow rate. This allows us to find plausible steady-state combinations of pressure drop, temperature, and mass flow.

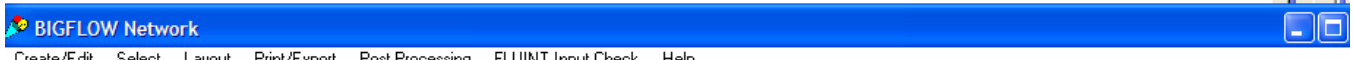

Create/Edit Select Layout Print/Export Post Processing FLUINT Input Check Help

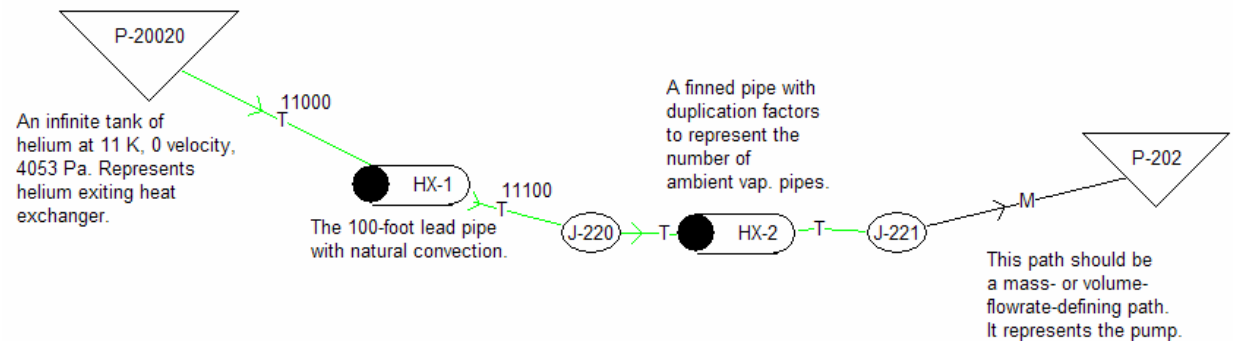

The "HX-1" macro is the 10" pipe with natural convection. The "HX-2" macro is a single pipe of the ambient vaporizer; a duplication factor is applied at both ends to represent a bank of some number of pipes.

\section{HX-1 and BigPipe}

HX-1 connects to the thermal submodel "BigPipe," a three-layer, 100-axial division model of the steel pipe wall. Thermal properties (heat capacity and thermal conductivity) of the steel are calculated from arrays of temperature, property pairs (arrays 1 and 2, respectively, of the submodel).

Convection between the pipe and wall is calculated by FLUINT.

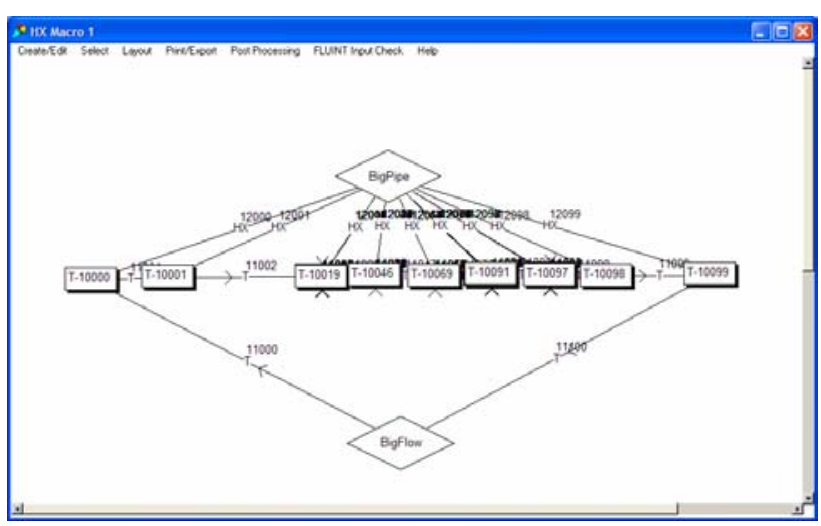

Axial and radial conduction within the pipe wall model are calculated with standard formulas. The subroutine "NCHCT" calculates a separate convection coefficient for each out-layer lump of the wall. (This subroutine is based on natural convection from a horizontal cylinder.)

Simulations showed that the outer layer of the metal, if open to free convection, was generally above $200 \mathrm{~K}$ in temperature.

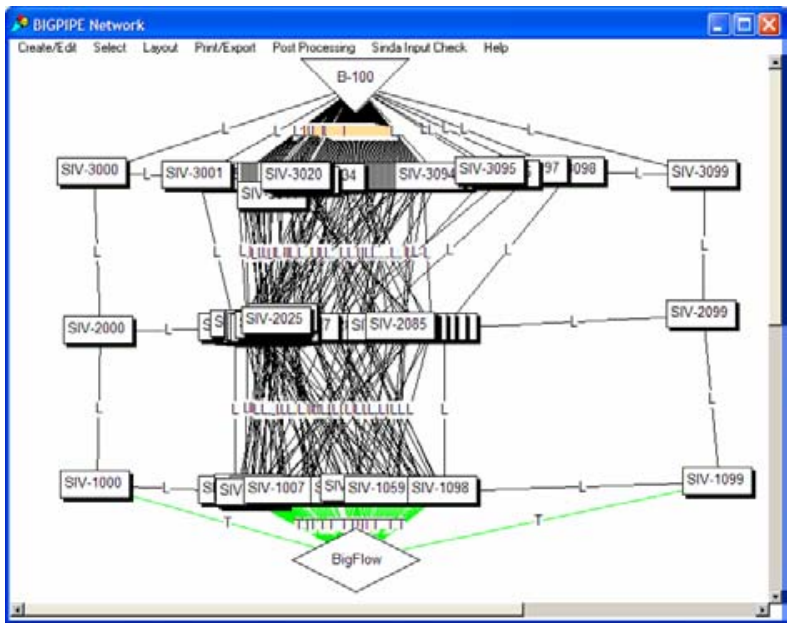




\section{HX-2, SmPipe01, and vapfin01}

The HX-2 macro is duplicated according to the register "sp_rep." it represents a single pipe of the ambient vaporizer, made of aluminum.

No convection directly off the pipe wall is included. All heat exchanged with the environment is done through the fin model "vapfin01," and the heat exchange seen by the tube is multiplied by the number of fins defined by the register "fins_per."

Vapfin01 represents five long, vertical stripes of metal along the fin. Because heat exchange from a vertical plate is not a linear function of height, it is unfortunately necessary to assume a single temperature along each of these stripes. The five subdivisions exist because SINDA has no subroutine for fin efficiency. Each fin is assumed to be standing alone in the ambient environment. Calculations of the netual convection off the fins are done is "Variables 1" of the fin submodel.

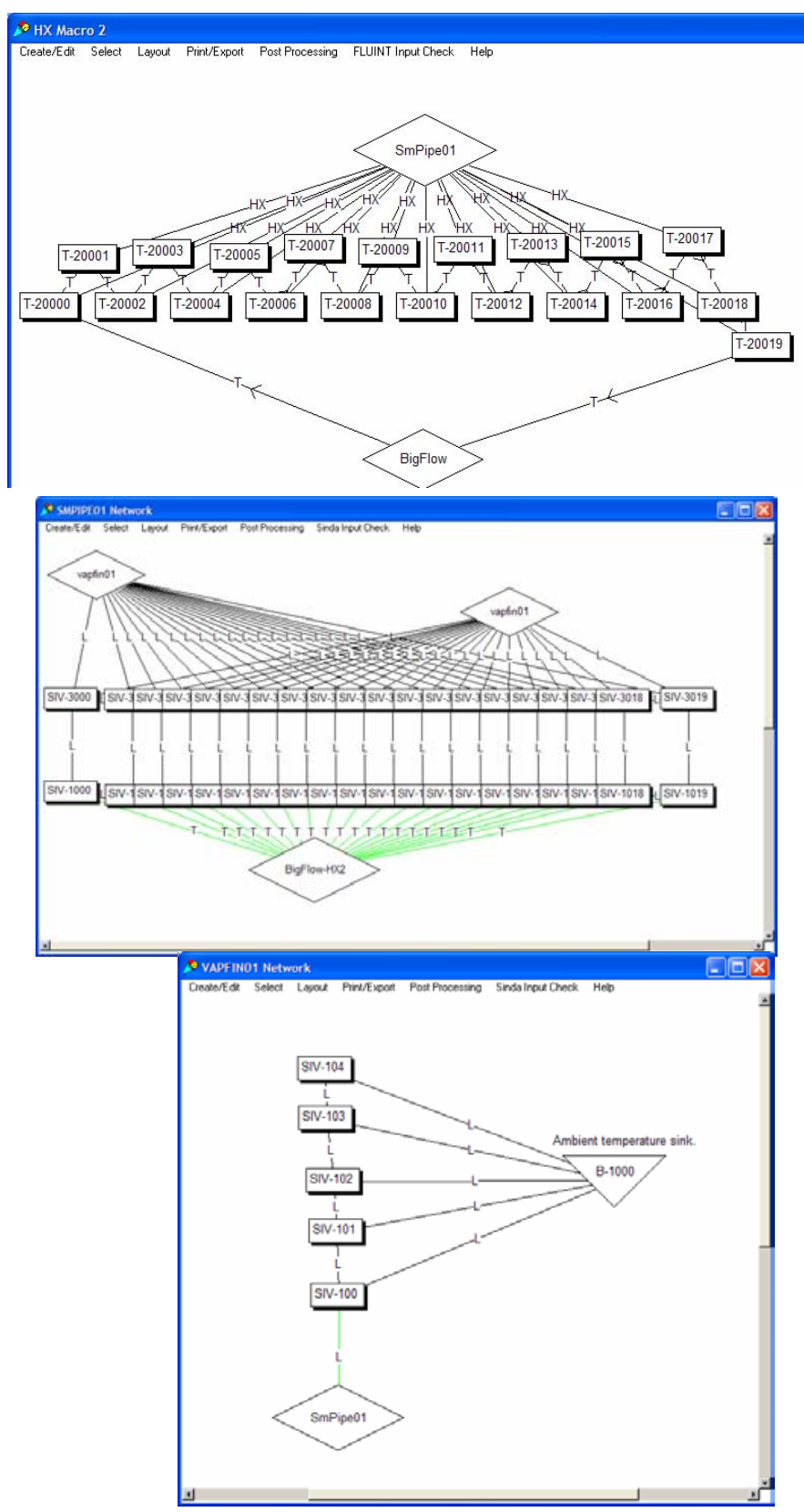




\section{$\underline{\text { Assumptions }}$}

- no losses in fittings

- identical parallel tubes is ambient vaporizer

- identical fins

- fins are free standing flat plates with vertical stripes of constant temperature

- pump represented as constant mass or volume flow rate

- ice either completely blocks a give section of pipe or has no effect at all.

\section{Future Improvements}

\section{$K$ factor of pipe splitting}

- from pg. A-29, Crane: 60fт for a sharp 90-degree bend

- from pg. A-29, Crane: $\mathrm{fT}=0.014$ for 10 -inch pipe

- $\mathrm{K}=0.84$

Could be included in the "FK" field of the entrance path to the HX submodel for the ambient vaporizer

- Other loss factors

- More complex feed system model

- More fluid properties down to correct start temperature (Complete property tables were only available down to $11 \mathrm{~K}$, with an always-gas assumptions) (Current properties from Cullimore \& Ring)

- account for interaction between fins

\section{Registers}

$\mathrm{sp}_{-} *$ : Registers related to the pipes in the ambient vaporizer

$\mathrm{k}^{*}$ : Equations for conduction factors $(\mathrm{A} / \mathrm{x}$, radial conduction)

fin $*$ : Fin properties

$\mathrm{T}^{*}$ : Temperatures 


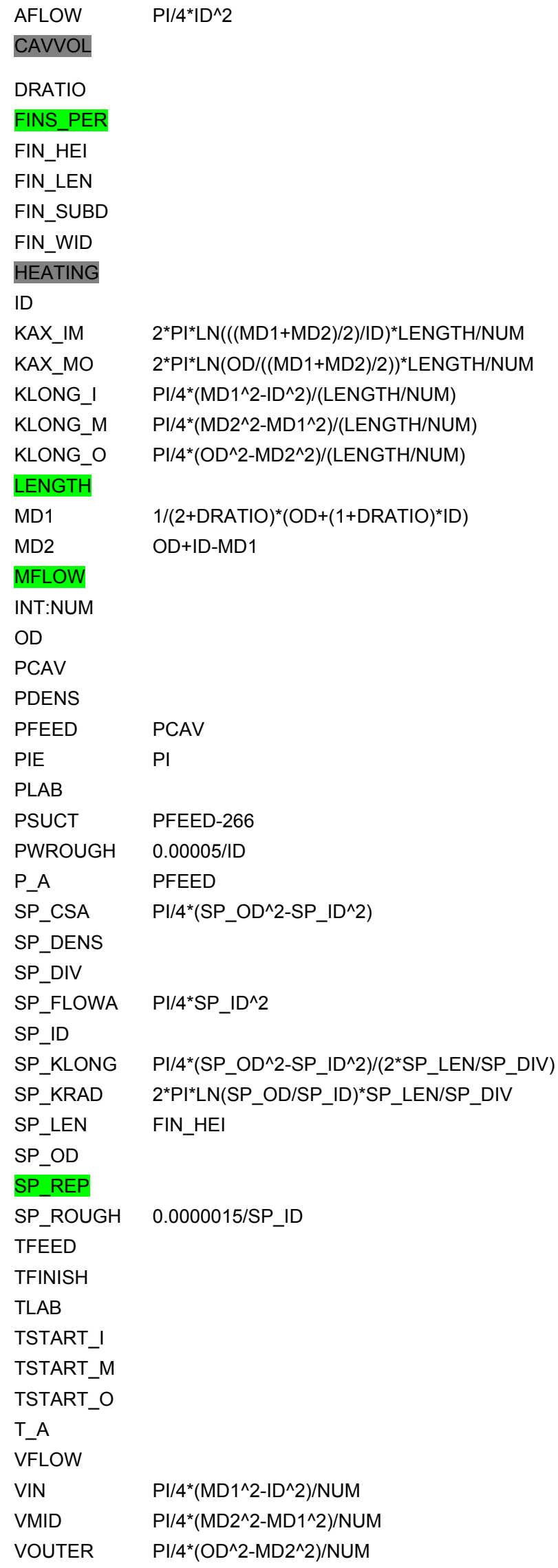


AFLOW: Cross-section flow area on 10" pipe

ID: The inner diameter (in meters) of the 10" pipe

DRATIO: The ratio of the thickness of the inner and outer layers of the 10" pipe to the center layer. The outer layers were made thinner for temperature accuracy.

HEATING: Not currently in use; would be the steady-state rate of heat generation by the experiment. (A previous model had an experiment tank connected to a feed plenum; these were removed to simply the model.)

KAX_IM: $=2 \pi \cdot \ln \left(\frac{M D 1+M D 2}{2 \cdot I D}\right)$ This is the standard formula for conduction between

two radial levels. It calculates this for the inner two levels of the 10" pipe

LENGTH: Length of 10 " tube (assumed to be 100 feet).

MFLOW: When the final path (21022) in the BigPipe model is a mass flow rate-defining path, this value can be used to specify the mass flow rate (in $\mathrm{kg} / \mathrm{s}$ )

NUM: The number of axial lumps on the BigPipe model (this cannot be changed dynamically; the lumps must be added or removed by hand to match this number if it is changed!)

OD: The outer diameter (in meters) of the 10" pipe

P_A: The pressure in the source plenum

PCAV: In a previous version of the model, this was the pressure in the experimental cavity.

PFEED: In a previous version of the model, this was the pressure of the helium source feeding into the experiment cavity.

PIE: FORTRAN doesn't understand "pi."

PLAB: The ambient pressure is used in natural convection calculations only.

PSUCT: In a previous model, there was a fixed suction pressure. This was impractical as a pump model, but this value is still used in the end plenum.

PWROUGH: Pipe wall relative roughness for the 10" (Schedule 20) pipe

SP_CSA: The cross-sectional area of the metal annulus in the vaporizer pipes is used to calculate axial heat transfer and volume.

SP_REP: This is one of the most important user-adjusted values. This determines the number of parallel vaporizer pipes, each of which will experience identical fluid flow. Fractions are acceptable, but I don't know why you would do that.

SP_DIV: See "NUM."

TSTART_*: These values do not effect the steady-state results.

T_A: The temperature of the source plenum.

VFLOW: When the final path (21022) in the BigPipe model is a volume flow ratedefining path, this values can be used to specify the volume flow rate $\left(\right.$ in $\left.\mathrm{m}^{\wedge} 3 / \mathrm{s}\right)$

VMID: The volume of each lump of the central cylinder of the 10" pipe 


\section{$\underline{\text { Trial Runs }}$}

\begin{tabular}{|c|c|c|c|c|c|c|}
\hline & pipes & $\begin{array}{l}\text { Pressure at end } \\
\text { junction (Pa) } \\
\text { (tank } \\
\text { BigFlow.221, } \\
\text { immediately } \\
\text { before the } \\
\text { "pump") }\end{array}$ & $\begin{array}{l}\text { Temperature at end } \\
\text { junction }(\mathrm{K})\end{array}$ & $\begin{array}{l}\text { Temperature in first } \\
\text { lump of fin bank (K) }\end{array}$ & $\begin{array}{l}\text { Mass flow } \\
\text { rate }(\mathrm{g} / \mathrm{s})\end{array}$ & $\begin{array}{l}\text { Volume flow } \\
\text { rate }\left(m^{\wedge} 3 / s\right)\end{array}$ \\
\hline Limits & 12 & $>3800$ & $>280$ & & $>2$ & \\
\hline $\begin{array}{l}\text { Full lead tube } \\
\text { convection }\end{array}$ & 12 & 3777.51 & 285.94 & 263.196 & 2.52874 & 0.40 \\
\hline $\begin{array}{l}\text { Full lead tube } \\
\text { convection }\end{array}$ & 12 & 3826.49 & 291.707 & 278.411 & 2.00895 & 0.32 \\
\hline $\begin{array}{l}\text { No lead tube } \\
\text { convection }\end{array}$ & 12 & 3883.25 & 239.11 & 51.5726 & 2.4836 & 0.32 \\
\hline $\begin{array}{l}\text { No lead tube } \\
\text { convection }\end{array}$ & 12 & 3910.75 & 249.625 & 66.1659 & 1.8724 & 0.25 \\
\hline $\begin{array}{l}\text { No lead tube } \\
\text { convection }\end{array}$ & 36 & 3983.05 & 272.172 & 134.27 & 2.24 & 0.32 \\
\hline $\begin{array}{l}\text { No lead tube } \\
\text { convection }\end{array}$ & 36 & 3985.4 & 272.936 & 137.731 & 2.15147 & 0.308 \\
\hline $\begin{array}{l}\text { Lead tube } \\
\text { convection for } \\
\text { nodes } 50+\end{array}$ & 36 & 3979.93 & 288.835 & 252.556 & 2.03103 & 0.308 \\
\hline $50+$ & 36 & 3977.43 & 287.547 & 248.669 & 2.11826 & 0.32 \\
\hline $90+$ & 36 & 3981.6 & 276.32 & 167.969 & 2.20599 & 0.32 \\
\hline $75+$ & 36 & 3979.73 & 281.6 & 206.672 & 2.16388 & 0.32 \\
\hline $\begin{array}{l}\text { Full lead tube } \\
\text { convection }\end{array}$ & 36 & 3974.73 & 293.945 & 283.726 & 2.07106 & 0.32 \\
\hline $\begin{array}{l}\text { Mass flow set } \\
\text { (not volume), } 50+\end{array}$ & 12 & 3843.26 & 276.669 & 224.294 & 2.1 & \\
\hline Mass flow, 50+ & 24 & 3942.92 & 284.404 & 239.3 & 2.1 & \\
\hline Mass flow, 50+ & 18 & 3903.45 & 280.276 & 227.695 & 2.2 & \\
\hline Mass flow, 50+ & 16 & 3885.97 & 279.183 & 225.141 & 2.2 & \\
\hline Mass flow, 50+ & 48 & 3993.59 & 288.915 & 252.995 & 2.2 & \\
\hline Mass flow, 50+ & 24 & 3938.57 & 283.346 & 234.706 & 2.2 & \\
\hline
\end{tabular}




\section{Register Data for above chart}

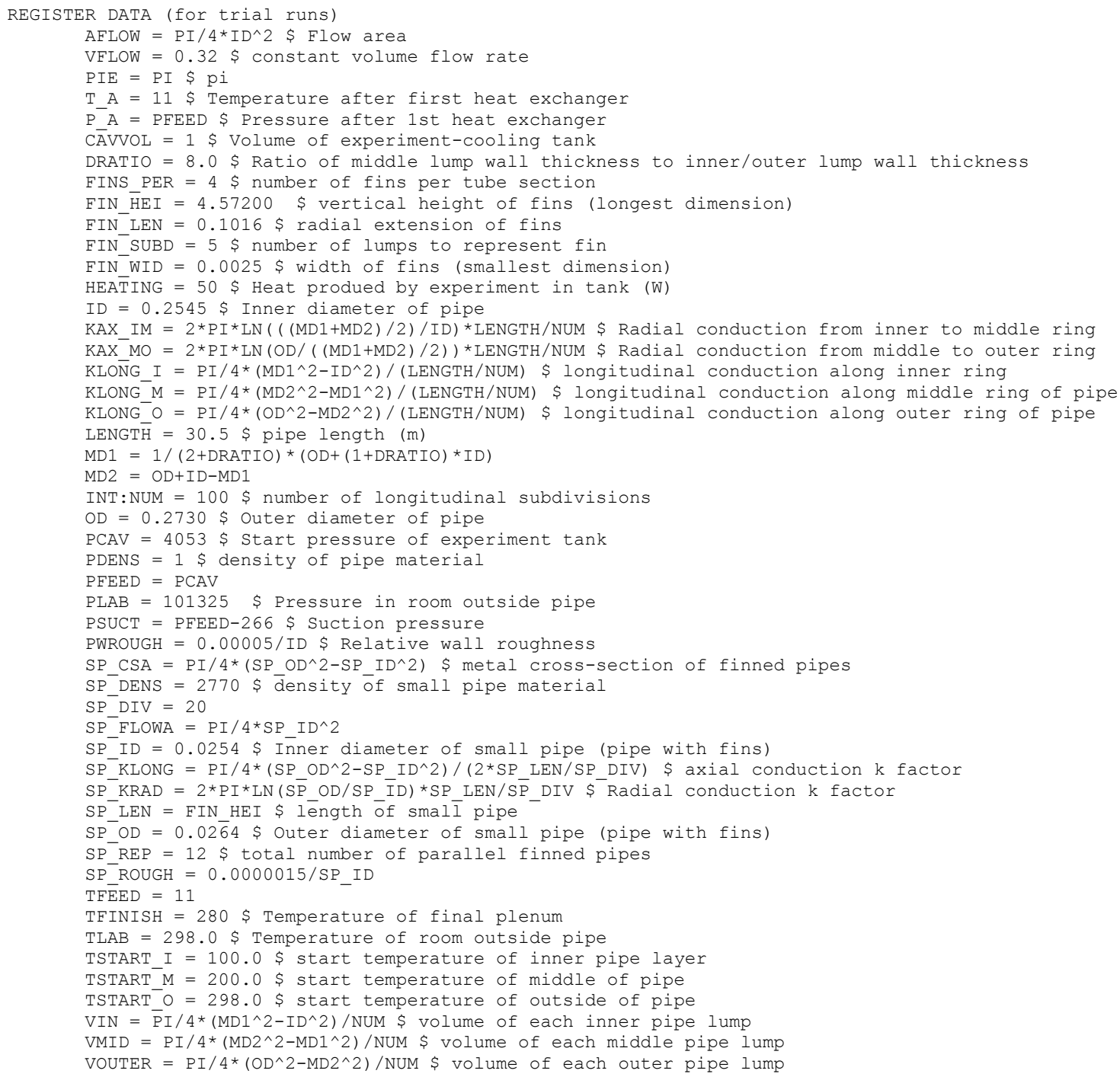




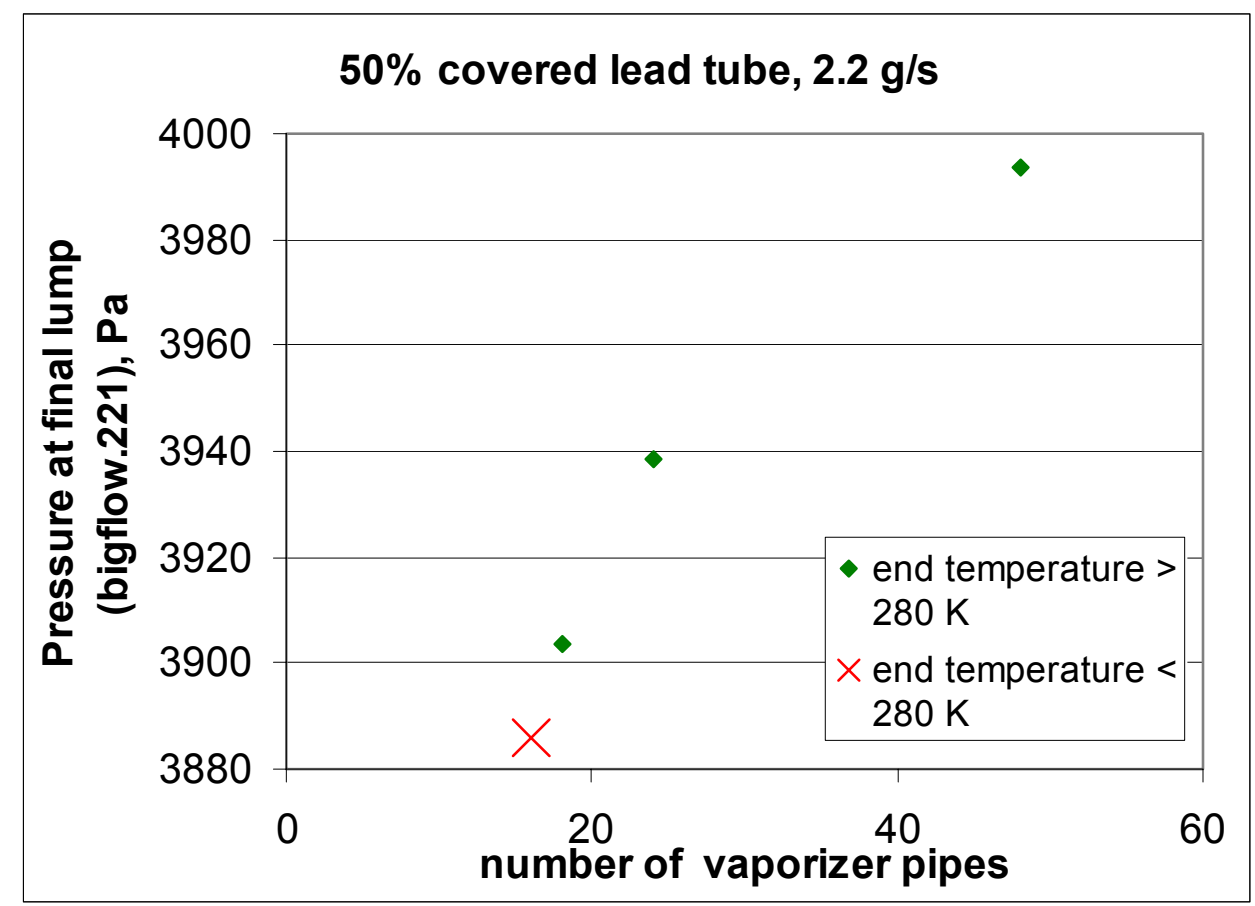

This graph shows different numbers of parallel vaporizer pipes and the resulting final pressures. Higher final pressure indicate lower pressure drops. There was a constant mass flow rate of $2.2 \mathrm{~g} / \mathrm{s}$.

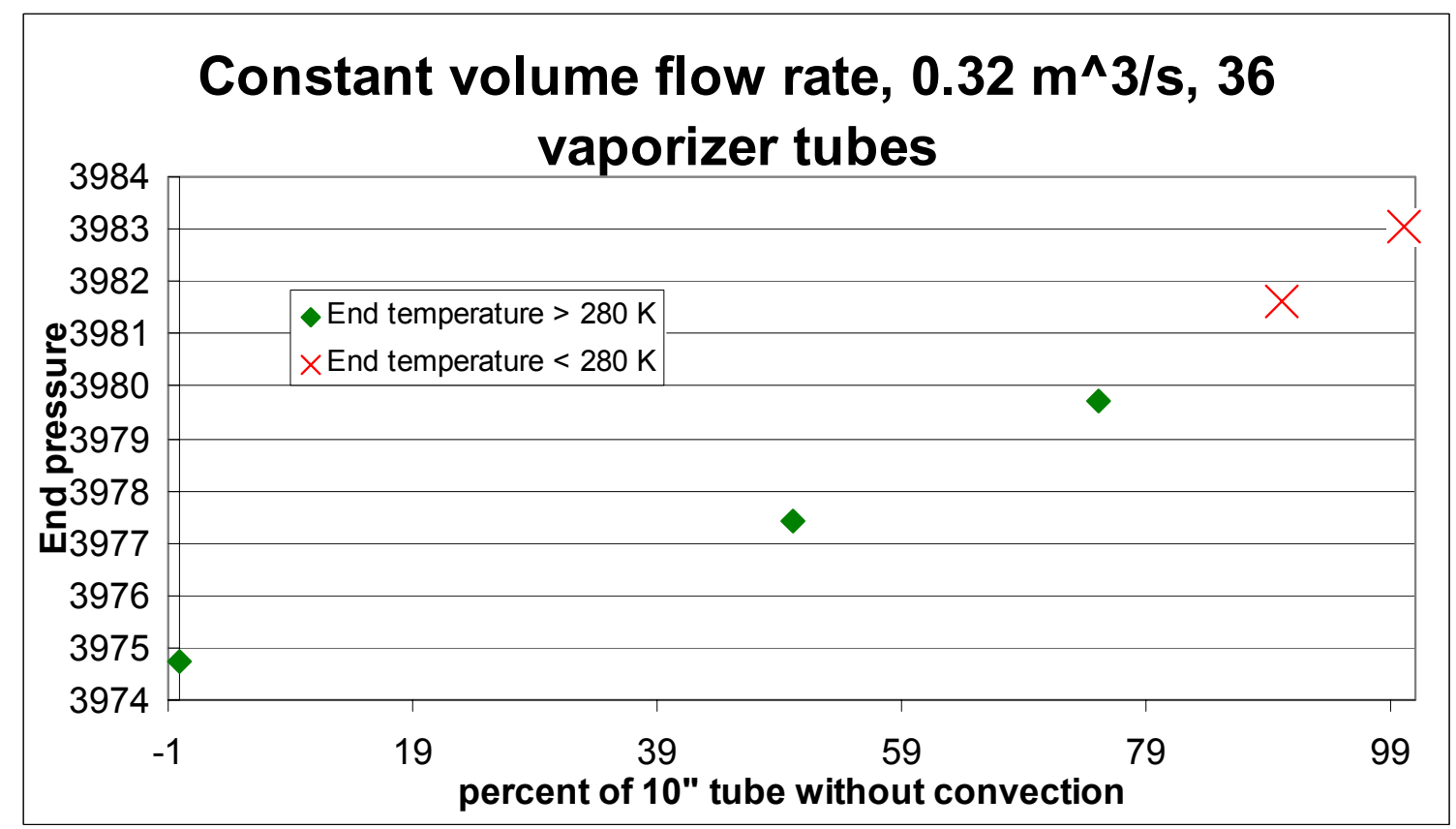

This graph shows how less pressure drop is needed if more of the 10" tube has no convection (or is iced), but that there is a cutoff around 75\% after which 36 ambient vaporizer tubes cannot heat the gas sufficiently. 


\section{References}

Crane Co, Flow of Fluids Through Valves, Fittings, and Pipe (Technical Paper No. 410 M). New York, 1986

Cullimore and Ring Technologies, Inc. http://www.crtech.com/properties.html . 2003:

Helium properties, air properties.

Fox, R. and McDonald, A. Introduction to Fluid Mechanics, $5^{\text {th }}$ ed. Wiley.

Holman, J.P. Heat Transfer, $9^{\text {th }}$ ed. 2001: McGraw-Hill 